BMJ Open

Sport \&

Exercise

Medicine

\title{
Appropriateness of the metabolic equivalent (MET) as an estimate of exercise intensity for post-myocardial infarction patients
}

\author{
Kate Woolf-May, ${ }^{1}$ Steve Meadows ${ }^{2}$
}

To cite: Woolf-May K, Meadows S. Appropriateness of the metabolic equivalent (MET) as an estimate of exercise intensity for postmyocardial infarction patients. BMJ Open Sport Exerc Med 2016;1: 0000172. doi:10.1136/bmjsem-2016000172

- Prepublication history and additional material is available. To view please visit the journal (http://dx.doi.org/ 10.1136/bmjsem-2016000172).

Accepted 7 December 2016

\section{(a) CrossMark}

${ }^{1}$ Human and Life Sciences, Canterbury Christ Church University, Canterbury, Kent, UK

${ }^{2}$ School of Sport \& Exercise Sciences, University of Kent, Chatham Maritime, Kent, UK

Correspondence to Dr Kate Woolf-May; kate. woolf-may@canterbury.ac.uk

\section{ABSTRACT}

Aims: To explore: (1) whether during exercise metabolic equivalents (METs) appropriately indicate the intensity and/or metabolic cost for post-myocardial infarction (MI) males and (2) whether post-exercise $\mathrm{VO}_{2}$ parameters provide insight into the intensity and/ or metabolic cost of the prior exercise.

Methods: 15 male phase-IV post-Mls $(64.4 \pm 6.5$ years) and 16 apparently healthy males $(63.0 \pm 6.4$ years) participated. Participants performed a graded cycle ergometer test (CET) of 50, 75 and $100 \mathrm{~W}$, followed by 10 min active recovery (at $50 \mathrm{~W}$ ) and 22 min seated recovery. Participants' heart rate (HR, bpm), expired air parameters and ratings of perceived exertion (exercise only) were measured.

Results: General linear model analysis showed throughout significantly lower HR values in post-MI participants that were related to $\beta$-blocker medication $\left(F_{(2,5)}=18.47, \mathrm{p}<0.01\right)$, with significantly higher $\mathrm{VCO}_{2} /$ $\mathrm{VO}_{2}\left(F_{(2.5)}=11.25, p<0.001\right)$ and gross $\mathrm{kcals} / \mathrm{LO}_{2} / \mathrm{min}$ $\left(F_{(2,5)}=11.25, p<0.001\right)$. Analysis comparing lines of regression showed, during the CET: post-MI participants worked at higher percentage of their anaerobic threshold (\%AT)/MET than controls $\left(F_{(2.90)}=18.98, p<0.001\right)$, as well as during active recovery $(100-50 \mathrm{~W})\left(F_{(2,56)}=20.81, \mathrm{p}<0.001\right)$; during seated recovery: GLM analysis showed significantly higher values of $\mathrm{VCO}_{2} \mathrm{NO}_{2}$ for post-MI participants compared with controls $\left(F_{(2,3)}=21.48, \mathrm{p}=0.001\right)$ as well as gross $\mathrm{kcals} / \mathrm{LO}_{2} / \mathrm{min}\left(F_{(2,3)}=21.48, \mathrm{p}=0.001\right)$.

Conclusion: Since METs take no consideration of any anaerobic component, they failed to reflect the significantly greater anaerobic contribution during exercise per MET for phase-IV post-MI patients. Given the anaerobic component will be greater for those with more severe forms of cardiac disease, current METs should be used with caution when determining exercise intensity in any patient with cardiac disease.

\section{INTRODUCTION}

Post-myocardial infarction (MI) patients make up the largest proportion of cardiac rehabilitation participants in England, ${ }^{1}$ and while considerable research has been conducted into the differences in physiological responses to exercise in those with

\section{What are the new findings?}

- The percentage anaerobic component per metabolic equivalent (\%AT/MET) is significantly higher for those with cardiac disease compared with healthy individuals.

- Current METs underestimate the exercise intensity and anaerobic demand of exercise for patients with cardiac disease.

- Reducing METs to account for body composition does not reliably address the issue of increased \%AT/MET for those with cardiac disease.

- Any value, indices or equation used in determining exercise intensity or in prescription of exercise for patients with cardiac disease, which does not consider the anaerobic component, should be used with caution.

more severe forms of heart disease, such as heart failure,,$^{2-5}$ there are still relatively few studies performed on those who have suffered MIs. ${ }^{6}$ In particular, among those who have completed cardiac rehabilitation and exercise regularly within the community (phase IV). Increasingly, researchers have questioned the use of equations and indices based on healthy individuals to estimate exercise intensity and assist in physical activity prescription in settings like cardiac rehabilitation. ${ }^{7-10}$

The primary aim of this study was to explore whether current metabolic equivalents (METs, 1 MET $\sim \mathrm{VO}_{2}$ of $3.5 \mathrm{~mL} / \mathrm{kg}$ / min) appropriately indicate exercise intensity and/or metabolic cost of exercise in phase-IV post-MI males. Additionally, research has shown postexercise measures of oxygen uptake parameters to provide insight into the intensity of the prior exercise in patients with cardiac disease. ${ }^{11}$ Therefore, a secondary aim was to observe whether postexercise measures provided further understanding into the intensity 
and/or metabolic cost of a bout of cycle ergometry when comparing phase-IV cardiac rehabilitation postMI patients with male controls.

\section{METHODS}

Ethical approval was provided by the local NHS Research Ethics Committee and the University Faculty of Social and Applied Science Research Ethics Committee, ref: 09/H1101/34.

\section{Power and sample size calculations}

Based on a previously observed statistically significant difference in $\mathrm{VO}_{2}$ of $2.3 \pm 1.8 \mathrm{~mL} / \mathrm{kg} / \mathrm{min}$ between people with cardiac disease and those with normal heart function during cycle ergometry, ${ }^{5}$ using Minitab statistical package (version 17), 15 participants were required in each group to achieve $90 \%$ power at an $\alpha$ of 0.05 .

\section{Participant recruitment}

Fifteen men classified with an uncomplicated MI $(4.7 \pm 3.2$ years since MI) were recruited through community phase-IV cardiac rehabilitation exercise classes. Sixteen apparently healthy volunteers were recruited from the same area through word of mouth and posters. All volunteers were given a Participant Information Sheet and interested individuals were asked to complete a Health and Physical Activity Screening Questionnaire. The post-MI volunteers were required to be 'uncomplicated', stable, at phase-IV cardiac rehabilitation level, taking standard medications, such as, statin, $\beta$-blocker, aspirin and ACE inhibitor. Potential controls were to be free of cardiac disease and/or event and/or chronic medical condition and/or taking long-term medications. All participants were required to be non-smoking, understand the nature of the study, aged between 50 and 75 years, perform similar levels of regular physical activity and free of any orthopaedic limitations during exercise. Participants that cleared screening were required to provide written informed consent and written acknowledgement of their participation from their general practitioner. Participants were free to withdraw from the study at any time without providing a reason.

\section{Procedures}

All data were collected in the same Exercise Laboratory. On arrival, each participant was measured for height (Stadiometer Seca 220, Seca, Hamburg, Germany) and body mass (Seca 710, Seca), thus body mass index was derived. Each participant then sat quietly for $10 \mathrm{~min}$ while measures of resting blood pressure (mm Hg) (Yamasu Mercurial Spygmomanometer 605P; Kenzmedico, Japan) and heart rate (HR, bpm) (Polar Model S810, Kempele, Finland, worn on strap around chest) were recorded in accordance with Association Chartered Physiotherapists in Cardiac Rehabilitation (ACPICR) ${ }^{12}$ guidelines for pre- exercise checks. Following these measures, respiratory function forced vital capacity and forced expiratory volume in $1 \mathrm{~s}$ was recorded by forced exhalation into a portable Spirometer. A total of three spirometry tests were performed with short recovery, and the best was recorded.

Prior to each participant's assessments, equipment was calibrated. To provide an indication of pre-exercise resting $\mathrm{VO}_{2}$, expired air was collected via a Hans Rudolph breathing valve (2700; Hans Rudolph, Kansas City, MO, USA) and plastic tubing into a Douglas bag (Model 6170, $170 \mathrm{~L}$ capacity non-diffusing gas collection bag, Hans Rudolph). A nose clip was worn and each participant sat quietly for $5 \mathrm{~min}$. The final minute of collection was used in analysis. The expired gas was analysed using a gas analyser (Servomex, West Sussex, UK). The expired volume of air was measured using a dry gas meter (Harvard Apparatus, Kent, UK) by evacuating each Douglas bag using a vacuum pump.

\section{Upright cycle ergometer test}

During cycle ergometer test (CET), active recovery and seated recovery, $\mathrm{VO}_{2}$ and $\mathrm{CO}_{2}$ production were measured using the Douglas bag method, the 'gold standard' for measuring efficiency, ${ }^{13}$ coefficient of variation was $<0.5 \%$ for both $\mathrm{O}_{2}$ and $\mathrm{CO}_{2},{ }^{14}$ methods previously described. Expired gases were collected over the final minute of each 6 min wattage stage and during active and seated recovery, along with ratings of perceived exertion (RPE) Borg 6-20 scale ${ }^{15}$ (exercise only). The gross energetic equivalent/metabolic cost of $\mathrm{VCO}_{2} / \mathrm{VO}_{2}$ was calculated using data from non-protein respiratory quotient, regression equation: $\mathrm{kcal} / \mathrm{LO}_{2} / \mathrm{min}=1.2411 \mathrm{xVCO}_{2} /$ $\mathrm{VO}_{2}+3.8076, \mathrm{R}^{2}=0.9996 .^{16}$

This study adopted a methodology in accordance with recommendations for exercise testing cardiac populations, ${ }^{12}$ including an extended postexercise period, as patients with cardiac disease require more time to return to pre-exercise levels. ${ }^{17} 18$ The protocol was designed to address criticisms of previous studies ${ }^{19-21}$; therefore, measures were taken comparing gross efficiency in patients and controls at the same 'absolute' workloads to gain a 'truer' indication of exercise cost. ${ }^{22}$ Following pre-exercise resting measures, each participant undertook the CET. This was performed on a SRM cycle erogmeter (Schoberer Rad Messtechnik, Julich, Germany) with seat height adjusted to ensure that participants' knees were slightly bent when the pedal was at the bottom of the crank stroke. Exercise started at a low intensity acting as a warm-up. ${ }^{12}$ Exercise intensity was increased every 6 min until three incremental levels were completed (50, 75 and $100 \mathrm{~W}$, respectively). Cadence was set at 60 revolutions per minute (rpm), shown to be most economical across a range of power outputs. ${ }^{22-24}$ Therefore, in line with recommendations, termination point should have been just below maximum 
Table 1 Participant characteristics at baseline, mean \pm SD (range)

\begin{tabular}{|c|c|c|}
\hline & Post-Mls ( $n=15$, mean \pm SD (range)) & Controls ( $n=16$, mean \pm SD (range)) \\
\hline Age (years) & $64.4 \pm 6.5(53-73)$ & $63.0 \pm 6.4(51-73)$ \\
\hline Height (m) & $1.78 \pm 0.06(1.64-1.91)$ & $1.76 \pm 0.07(1.63-1.85)$ \\
\hline Body mass (kg) & $88.4 \pm 13.5$ (64.5-113.0) & $83.1 \pm 10.5(65.5-98.0)$ \\
\hline BMI $\left(\mathrm{kg} / \mathrm{m}^{2}\right)$ & $27.7 \pm 3.7(20.6-36.5)$ & $26.6 \pm 3.2(18.9-32.0)$ \\
\hline \multicolumn{3}{|l|}{ Pre-exercise resting } \\
\hline $\mathrm{SBP}(\mathrm{mm} \mathrm{Hg})$ & $131.8 \pm 14.0(112-159)$ & $139.3 \pm 14.1(121-161)$ \\
\hline $\mathrm{DBP}(\mathrm{mm} \mathrm{Hg})$ & $78.9 \pm 7.0(69-94)$ & $82.7 \pm 7.6(69-96)$ \\
\hline $\mathrm{HR}(\mathrm{bpm})$ & $58.7 \pm 7.4(48-73)^{*}$ & $70.3 \pm 10.9(55-89)$ \\
\hline $\mathrm{VO}_{2}(\mathrm{~mL} / \mathrm{kg} / \mathrm{min})$ & $3.47 \pm 0.57(2.31-4.31)$ & $3.61 \pm 0.56(2.24-4.38)$ \\
\hline $\mathrm{VO}_{2}(\mathrm{~L} / \mathrm{min})$ & $0.31 \pm 0.05(0.28-0.37)$ & $0.30 \pm 0.02(0.18-0.37)$ \\
\hline $\mathrm{VCO}_{2}(\mathrm{~L} / \mathrm{min})$ & $0.32 \pm 0.09(0.15-0.44)$ & $0.30 \pm 0.12(0.14-0.64)$ \\
\hline VE (L/min) & $11.9 \pm 4.4(6.3-19.7)$ & $9.86 \pm 3.4(5.1-18.9)$ \\
\hline $\mathrm{kcal} / \mathrm{LO}_{2} / \mathrm{min}$ & $5.25 \pm 0.13(5.01-5.36)$ & $5.25 \pm 0.08(5.12-5.36)$ \\
\hline RPP (HRxSBP (mm Hg)) & $7692 \pm 990(6426-10176)^{\dagger}$ & $9749 \pm 1504$ (7112-11932) \\
\hline $\mathrm{VCO}_{2} / \mathrm{VO}_{2}(\mathrm{~L} / \mathrm{min})$ & $1.02 \pm 0.18(0.74-1.37)$ & $0.96 \pm 0.24(0.77-1.75)$ \\
\hline FVC & $4.4 \pm 0.9(3.5-6.8)$ & $4.5 \pm 0.7(3.3-5.7)$ \\
\hline $\mathrm{FEV}_{1}$ & $3.2 \pm 0.5(2.4-4.2)$ & $3.4 \pm 0.6(2.5-4.5)$ \\
\hline \multicolumn{3}{|l|}{ Weekly physical activity (self-reported) } \\
\hline 30 min sessions at moderate intensity & $4.6 \pm 2.0(1-7)^{\dagger}$ & $2.8 \pm 1.8(0-7)$ \\
\hline 20 min sessions at vigorous intensity & $1.6 \pm 1.2(0-5)$ & $1.4 \pm 1.5(0-4)$ \\
\hline
\end{tabular}

*Statistically significantly different from controls at $p \leq 0.05$.

† Statistically significantly different from controls at $p \leq 0.01$.

$\mathrm{BMI}$, body mass index; DBP, diastolic blood pressure; $\mathrm{FEV}_{1}$, air volume exhaled at the end of the first second of forced expiration/forced expiratory volume in $1 \mathrm{~s}$; FVC, forced vital capacity; $\mathrm{HR}$, heart rate; $\mathrm{kcal} / \mathrm{LO}_{2} / \mathrm{min}$, kilocalories per litre of oxygen uptake per minute; RPP, rate pressure product; $\mathrm{SBP}$, systolic blood pressure; $\mathrm{VCO}_{2}$, carbon dioxide expired; $\mathrm{VO}_{2}$, oxygen uptake; VE, minute ventilation.

intensity. ${ }^{12}$ This was immediately followed by $10 \mathrm{~min}$ active recovery at $50 \mathrm{~W}$ with $60 \mathrm{rpm}$.

\section{Postexercise $\mathrm{VO}_{2}$ parameters}

After active recovery, participants were seated, expired air continued to be collected and measured during 10 th to 11 th and 21 st to 22 nd min.

\section{Data analysis}

Statistical analysis was performed using Minitab statistical package (version 17), with a 5\% level of significance. Bonferroni correction factor was applied where appropriate, which shifted the point of statistical significance. Variability of data within a distribution was given as $1 \mathrm{SD}$ (mean $\pm \mathrm{SD})$. Baseline differences between groups were determined using an independent t-test. General linear model was used to compare differences in the measured variables between the groups during and post-CET. One-way analysis of variance was used post hoc to determine differences between groups at individual data collection points. $\mathrm{VCO}_{2} / \mathrm{VO}_{2}=1.0$ was used to describe point of anaerobic threshold (AT) as this has been shown to correlate highly with blood lactate values and deemed appropriate when testing patients with cardiac disease, where HR values are unreliable. ${ }^{25}$ Regression analysis comparing lines of trajectory determine the difference between percentages of AT (\%AT) versus METs relationship (\%AT/MET) between groups. All data were double checked for transcript errors.

\section{RESULTS}

\section{Participants}

Table 1 shows participant characteristics at baseline.

\section{Medications}

Since all post-MI participants were taking both $\beta$ blockers and a statin (all but one participant, table 2), the statistical effect of both were similar to the group effect. It is likely that the reduced HR values for the post-MI participants throughout were due to their $\beta$ blocker medication. There were few participants taking other medications (table 2) to determine any

Table 2 Number of post-Mls taking various cardiovascular medications

\begin{tabular}{lc}
\hline Medication & Number of post-Mls \\
\hline Aspirin & 12 \\
Clopidogrel & 4 \\
Warfarin & 1 \\
$\beta$-blocker & 15 \\
Statin & 14 \\
Fibrate & 1 \\
Ezetimibe & 1 \\
ACE inhibitor & 11 \\
Angiotensin receptor antagonist & 2 \\
$\alpha$-blocker & 1 \\
Potassium channel activator & 1 \\
\hline Mls, myocardial infarctions. &
\end{tabular}




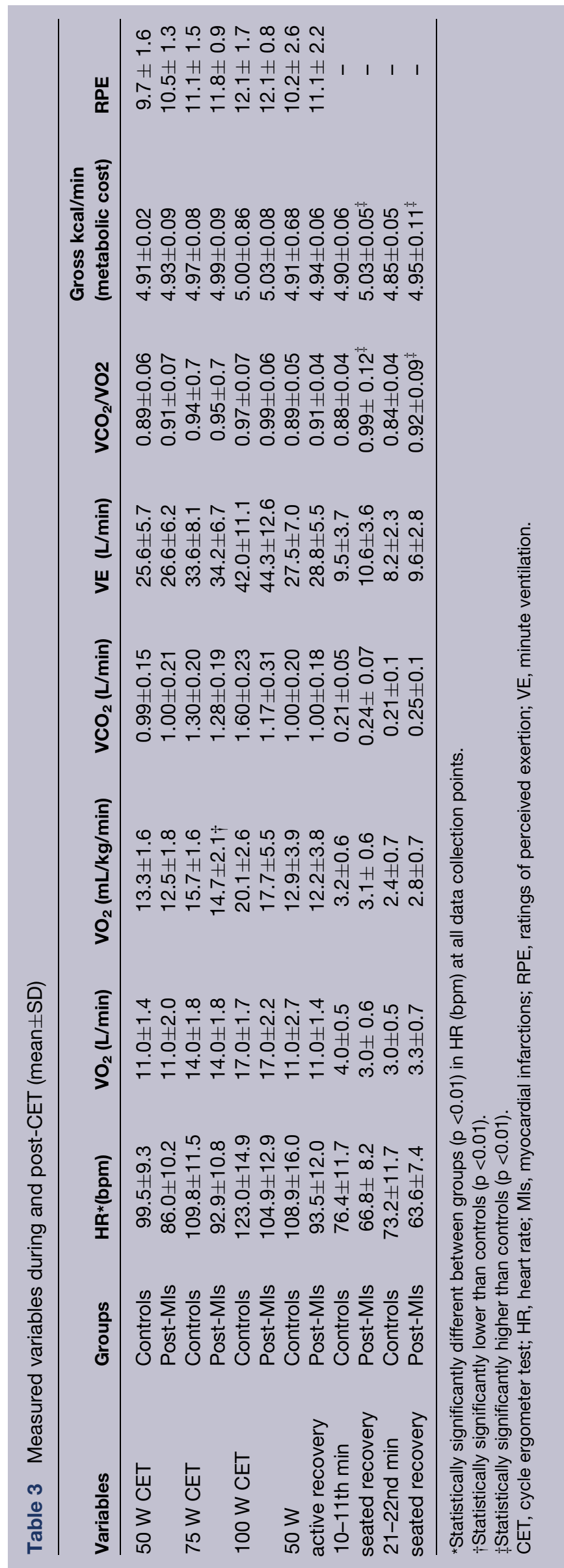

meaningful statistical effect on any of the measured variables.

\section{Cycle ergometer test}

Bonferroni shifted significance to $\mathrm{p}<0.017$, analysis revealed $\operatorname{HR}\left(F_{(2,3)}=17.64, \mathrm{p}<0.001\right)$ to be significantly lower in post-MI participants with no significant difference in any of the other measured variables between groups (table 3). Post-MIs participants reached $\mathrm{AT}^{25}$ at $\mathrm{VO}_{2} \quad 18.7 \quad \mathrm{~mL} / \mathrm{kg} / \mathrm{min} \quad(\mathrm{AT}=68.60 \times 1.0-49.95$, $\left.\mathrm{R}^{2}=0.998\right)$ compared with $22.8 \mathrm{~mL} / \mathrm{kg} / \mathrm{min}$ for controls (AT $\left.=87.91 \times 1.0-65.10, \mathrm{R}^{2}=0.996\right)$, which were significantly different after Bonferroni shifted significance to $\mathrm{p}<0.001\left(F_{(2,90)}=43.99, \mathrm{p}<0.001\right) ; \%$ AT/MET relationship showed a significantly greater anaerobic component per MET for the post-MI participants compared with controls $\left(F_{(2,90)}=18.98, \mathrm{p}<0.001\right)$.

\section{Active recovery (100-50 W)}

Bonferroni shifted significance to $\mathrm{p}<0.025$, HR $\left(F_{(2,2)}=17.59, \quad \mathrm{p}<0.001\right)$ was significantly lower for post-MI participants, with no significant differences in any other measured variables. Analysis comparing \% AT/METs relationship, where Bonferroni shifted significance to $\mathrm{p}<0.00$, showed that $\%$ AT/MET was again significantly greater for post-MIs $\left(\mathrm{F}_{(2,56)}=20.81\right.$, $\mathrm{p}<0.001)$.

\section{Seated recovery}

Bonferroni shifted significance to $\mathrm{p}<0.017$, HR was significantly lower $\left(F_{(2,3)}=17.59, \mathrm{p}<0.001\right)$ for post-MI participants, with greater $\mathrm{VCO}_{2} / \mathrm{VO}_{2} \quad\left(F_{(2,3)}=21.48\right.$, $\mathrm{p}=0.001)$ and gross $\mathrm{kcal} / \mathrm{LO}_{2} / \mathrm{min}$ values $\left(F_{(2,3)}=21.48\right.$, $\mathrm{p}=0.001)$. Analysis comparing \%AT/METs relationship showed no significant difference between groups. However, post-MI participants showed higher $\mathrm{VCO}_{2} /$ $\mathrm{VO}_{2}$ and subsequent gross $\mathrm{kcal} / \mathrm{LO}_{2} / \mathrm{min}$ compared with controls during the 11th $\left(F_{(2,10)}=11.14, \mathrm{p}=0.002\right)$ and 22nd $\min \left(F_{(2,10)}=11.21, \mathrm{p}=0.002\right) \quad$ (table 3$)$.

\section{CET, active and seated recovery}

Bonferroni shifted significance to $\mathrm{p}<0.001, \% \mathrm{AT} /$ METs was significantly greater throughout for postMI participants compared with controls $\left(F_{(2,90)}=9048.0, \mathrm{p}<0.000\right)$ (figure 1$)$, with significantly greater gross $\mathrm{kcal} / \mathrm{LO}_{2} / \min \left(F_{(2,179)}=16.22, \mathrm{p}<0.001\right)$.

\section{DISCUSSION}

Throughout the CET and active recovery there were no significant differences between groups in RPE, $\mathrm{VO}_{2}$ parameters or derived METs. Therefore on first inspection, current METs would appear to appropriately estimate exercise intensity for the phase-IV postMIs. However, METs are based on multiples of relative measures of resting $\mathrm{VO}_{2}$, which of course takes no account of any anaerobic component. On this basis, the assumption is that the anaerobic component per MET 


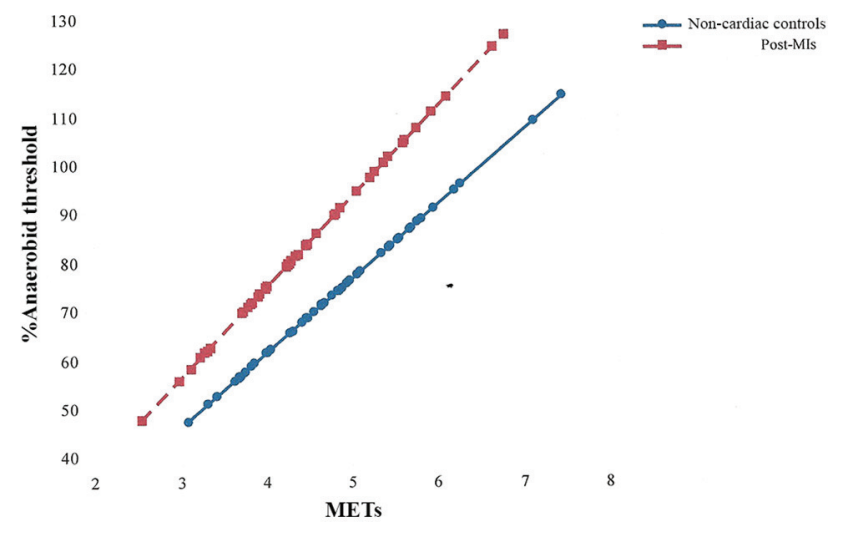

Figure 1 Percentage of anaerobic threshold-metabolic equivalent (MET) relationship throughout cycle ergometry, active and seated recovery, for post-myocardial infarction (MI) patients versus non-cardiac controls.

would be similar across populations. Yet, our findings show this not to be so, as post-MI participants clearly worked at a significantly higher percentage of their $\mathrm{AT}^{25}$ per MET when compared with the controls across the exercise intensity range (figure 1).

\section{Increased anaerobic metabolism}

Using the same statistical methods, reanalysis was conducted on data taken from two published studies ${ }^{10} 26$ and from another paper $^{27}$ that compared phase-IV post-MI males with non-cardiac controls during graded exercise. The findings revealed that irrespective of different physiological and RPE responses, for all studies, post-MIs worked more anaerobically per MET (\%AT/MET), with varying degrees of heteroscedasticity between studies as exercise intensity increased. For example, Meadows and Woolf-May ${ }^{10}$ found that during a treadmill walking protocol of speeds 2.0-4.4 miles/hour (figure 2), 17 post-MI participants (aged $63.0 \pm 8.5$ years) produced significantly higher $\mathrm{VO}_{2} \mathrm{~mL} / \mathrm{kg} / \mathrm{min}$ values than 17 non-cardiac males (aged $51.9 \pm 7.7$ years) $\left(F_{(2,8)}=5.25, \mathrm{p}<0.05\right)$ with no significant differences in $\mathrm{VCO}_{2} / \mathrm{VO}_{2}$ or $\mathrm{HR}$.

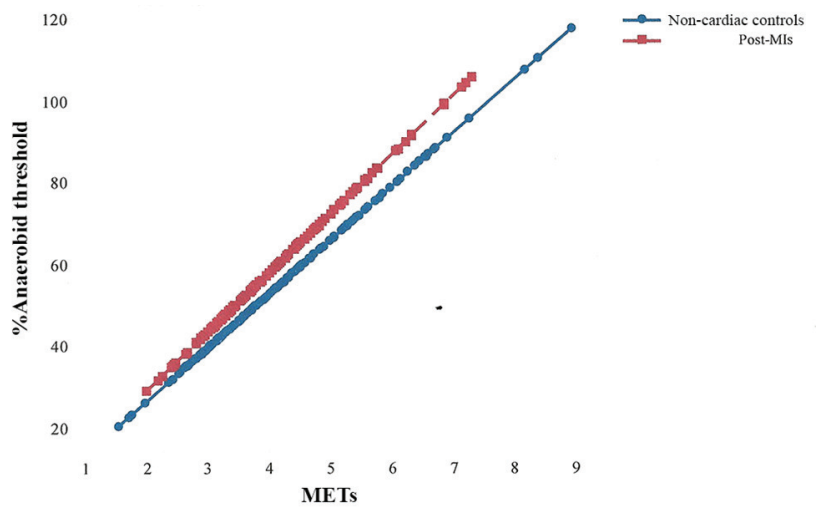

Figure 2 Percentage of anaerobic threshold-metabolic equivalent (MET) relationship during graded treadmill walking for post-myocardial infarction (MI) patients versus noncardiac controls. ${ }^{10}$

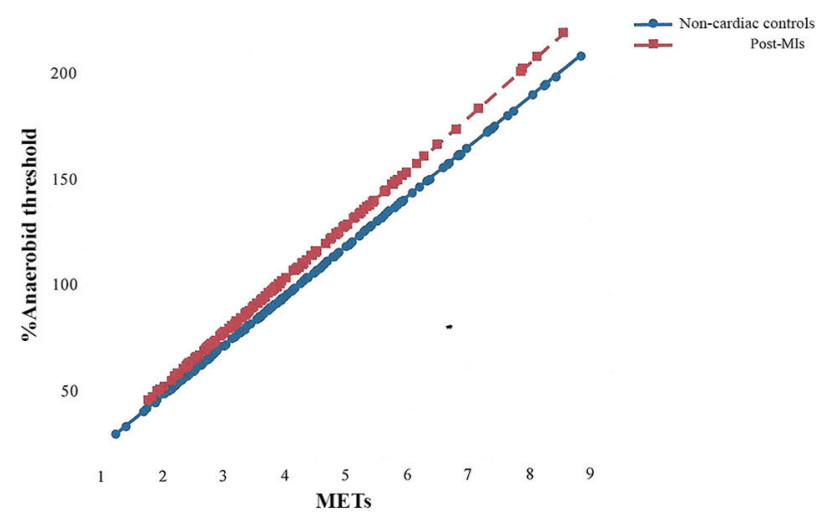

Figure 3 Percentage of anaerobic threshold-metabolic equivalent (MET) relationship during the $10 \mathrm{~m}$ shuttle walking test with cones for post-myocardial infarction (MI) patients versus non-cardiac controls. ${ }^{26}$

However, the study employing the Modified Bruce treadmill walking test, ${ }^{27}$ involving 20 post-MI participants (aged $64.4 \pm 5.8$ years) and 20 male controls (aged 59.8 \pm 7.6 years), showed no significant differences between groups in $\mathrm{VO}_{2} \mathrm{~mL} / \mathrm{kg} / \mathrm{min}$, again with no differences in $\mathrm{VCO}_{2} / \mathrm{VO}_{2}$ or $\mathrm{HR}$ but the \%AT/MET was significantly greater for the post-MI participants. ${ }^{28}$ Reanalysis of the findings from the study comparing two different 10-m shuttle walking test (SWT) protocols (one using cones around which to turn, figure 3, and the other without, figure 4$),{ }^{26}$ also using 20 post-MI participants (aged $64.8 \pm 6.6$ years) and 20 male controls (aged $64.1 \pm 5.7$ years), showed that during the 10-m SWT with cones, no significant differences in $\mathrm{VO}_{2}$ parameters were observed, but RPE was higher for post-MI participants $\left(F_{(2,10)}=4.78, \mathrm{p}<0.05\right)$. During the 10-m SWT with no cones however, post-MI participants displayed significantly greater $\quad \mathrm{VCO}_{2} / \mathrm{VO}_{2}$ $(F=23.51, \mathrm{p}<0.01)$ and $\operatorname{RPE}(F=4.78, \mathrm{p}<0.05)$ values than the controls. For both $10-\mathrm{m}$ SWT protocols, HR values in post-MI participants were significantly lower $\left(F_{(2,10)}=72.2, \quad \mathrm{p}<0.05\right), \quad$ likely due to $\beta$-blocker medication. ${ }^{26}$

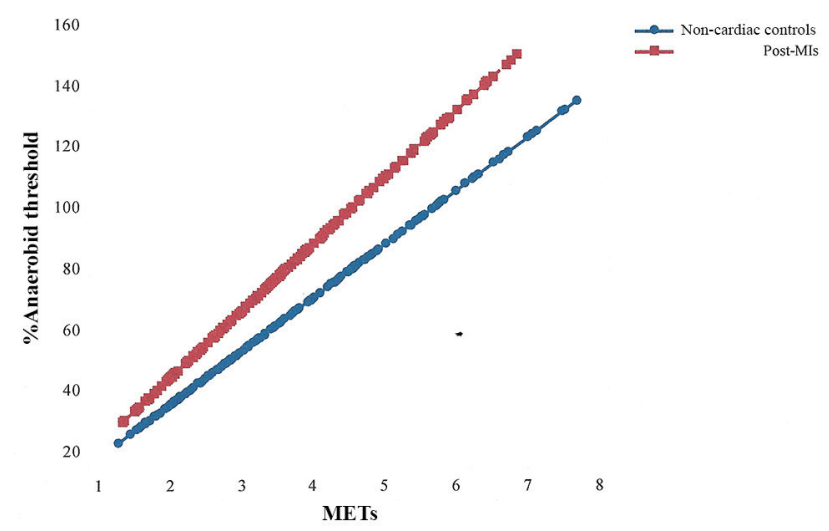

Figure 4 Percentage of anaerobic threshold-metabolic equivalent (MET) relationship during the $10 \mathrm{~m}$ shuttle walking test without cones for post-myocardial infarction (MI) patients versus non-cardiac controls. ${ }^{26}$ 
Although it is clear that the single marker of $\mathrm{VCO}^{2} /$ $\mathrm{VO}^{2}$ equal to 1.0 may not be considered a 'true' indicator of AT, as shown by the high y axis figures seen in figures 1-4, it does however represent an important shift in metabolism. The fact that all post-MI participants of these studies work at a higher \%AT/MET is not to be unexpected, as it has been known since the 1960 s that patients with cardiac disease reach the point where $\mathrm{VCO}_{2} / \mathrm{VO}_{2}$ equals 1.0 at a lower $\mathrm{VO}_{2}(\mathrm{~mL} / \mathrm{kg} /$ min) than their non-cardiac counterparts, ${ }^{29}$ and the more severe the heart disease, the sooner this point is reached. ${ }^{2}$ However, METs, which take no account of any anaerobic component are currently advocated by the British Association of Cardiac Prevention and Rehabilitation $^{30}$ and the American Association of Cardiovascular and Pulmonary Rehabilitation ${ }^{31}$ for use in the prescription of exercise and determination of exercise intensity to cardiac populations.

METs are often used synonymously to describe the exercise intensity and energy expenditure/metabolic cost of physical activity. While overall energy expenditure was statistically significantly higher for the post-MI participants in this study, pragmatically, this only equated to a mean of $0.06 \mathrm{kcal} / \mathrm{min}$. Yet, the anaerobic component per MET was undoubtedly greater for the post-MIs. For example, 5 METs, considered to be of moderate intensity, for this study equated to $76.8 \%$ AT for controls but 93.6\%AT for the post-MI participants. The difference of which increased with exercise intensity, as 7 METs, considered to be of vigorous intensity, equated to $101.5 \%$ AT for controls, but was $30 \%$ higher for post-MI participants at $131 \% \mathrm{AT}$, an intensity considered potentially hazardous for most of these patients.

During exercise, at and beyond the point where $\mathrm{VCO}_{2} / \mathrm{VO}_{2}$ equals 1.0 , metabolic acidosis increases exponentially. Therefore, for most patients with cardiac disease, who reach this point sooner, similar amounts of physical work would be more physically demanding in comparison to non-cardiac individuals. A study performed by Takagi $e t a l^{6}$ observed that for post-MI patients, even as soon as $21 \pm 8$ days postevent, the main factor limiting their exercise capacity was related to their inability to use oxygen rather than oxygen delivery per se, which was found due to skeletal muscle deoxygenation abnormalities. The outcome resulting in a slowing in oxygen kinetics, ${ }^{32}$ causing greater reliance on anaerobic metabolism to meet the demands of the physical work. ${ }^{33}$ Although similar findings are well reported in those classified with heart failure, ${ }^{29} 3234$ there are relatively few reported studies showing this in more physically able patients with cardiac disease, such as phase-IV cardiac patients.

The increased reliance on anaerobic processes in patients with cardiac disease is well reported and largely multifactorial, potentially involving reductions in cardiac output, neurohormonal/cytokine activation and/or changes in skeletal muscle blood flow. ${ }^{6} 3536$
Decreases in 'efficient' oxidative (type 1) skeletal muscle fibres, oxidative enzymes, mitochondrial density and muscle atrophy are mostly reported in those with chronic heart failure ${ }^{35-38}$ along with reduced phosphocreatine stores and 50\% higher ATP consumption, ${ }^{3}$ all contributing to metabolic skeletal muscle inefficiency. ${ }^{39}$ However, skeletal muscle morphology can also occur in those with mild heart failure, ${ }^{37}$ causing a higher reliance on anaerobic processes $^{11} 20$ and greater energy expenditure. ${ }^{3}$ Animal studies indicate the extent of these changes are likely dependent on the size of MI and amount of left ventricular dysfunction. ${ }^{36}$

Whether the medications taken by the post-MIs were influential on our findings is difficult to determine. As discussed in previous publications, ${ }^{8}{ }^{10}$ both statins and certain $\beta$-blocker medications can result in increased reliance on anaerobic metabolism. $\beta$-blockers are known to alter cardiorespiratory response by slowing HR, thus affecting oxygen kinetics ${ }^{40}{ }^{41}$ and reduce skeletal muscle blood flow, consequently increasing general fatigue. ${ }^{42} \beta$-blockers have also been found to have similar depressive effects on lipolysis as statins $^{43} 44$ and therefore potentially contributed towards any shift towards anaerobic metabolism. The very same participants taking $\beta$-blockers in this study were also taking statins, thus producing statistically similar results. High-dose statins may also lead to muscle myopathy and interfere with fatty acid oxidation, producing greater oxidation of carbohydrates, ${ }^{43}$ all potentially contributing to a shift towards anaerobic processes as observed in the post-MI participants.

\section{Body composition}

Some researchers have suggested that for specific populations the 1 MET value should be adjusted, especially for overweight ${ }^{45} 46$ and cardiac populations. ${ }^{7}$ Savage $e t a l^{7}$ suggested that for normal and overweight cardiac patients, the resting 1 MET should be reduced to a $\mathrm{VO}_{2}$ of $2.84 \mathrm{~mL} / \mathrm{kg} / \mathrm{min}$. To determine whether this would apply, secondary analysis of this and the other studies was performed. ${ }^{10} 2628$ Analysis showed a perfect correction in \%AT/MET between post-MIs and controls for this study, as for the Modified Bruce protocol, $^{28}$ and the $10-\mathrm{m}$ SWT without the cones ${ }^{26}$ $(p>0.05)$. However, for the $10-m$ SWT with the cones ${ }^{26}$ and treadmill walking study, ${ }^{10}$ the correction of 1 MET of $2.84 \mathrm{~mL} / \mathrm{kg} / \mathrm{min}$ reversed the significant difference, as controls now showed a greater \%AT/ MET ( $p<0.05$ ). Thus indicating the adjustment to overcompensate for certain protocols, suggesting body composition not to be the only influential factor in MET differences between cardiac and non-cardiac populations.

During the Modified Bruce study, body composition of the participants was measured. ${ }^{28}$ Analysis showed only lean body mass to be influential, having a significant effect on breathing frequency $\left(F_{(2,5)}=6.71\right.$, 
$\mathrm{p}<0.01)$. However, this was not sufficient to influence the significantly higher breathing frequency observed in the post-MI participants $\left(F_{(2,5)}=19.74, \mathrm{p}<0.01\right)$, which was not accompanied with significant differences in minute ventilation $(\mathrm{L} / \mathrm{min})$ between groups. The major factor to influence breathing frequency is usually blood $\mathrm{CO}_{2}$ levels, leading to lowering in $\mathrm{pH}$ as $\mathrm{CO}_{2}$ increases. $^{37}$ Therefore, the increased breathing frequency of the post-MI would indicate the use of enhanced anaerobic metabolism. ${ }^{28}$

\section{Postexercise}

Despite there being no observed differences in parameters of $\mathrm{VO}_{2}$ during the CET or active recovery, during seated recovery, compared with controls, the post-MI participants produced significantly elevated $\mathrm{VCO}_{2} / \mathrm{VO}_{2}$ values, taken during the 11 th and 22nd min of expired gas collection (table 3). This would indicate a slowing in their $\mathrm{O}_{2}$ kinetics, producing higher proportions of $\mathrm{CO}_{2}$, which continued for some time after exercise had ceased.

In summary, it is clear that during exercise, current METs, or METs adjusted for body weight, do not consistently reflect the significantly higher anaerobic component per MET observed in phase-IV post-MIs when compared with the controls. Since the anaerobic component is likely greater for patients with more severe heart disease, any value, indices or equation used in determining exercise intensity or in prescription of exercise to cardiac patients, which does not consider the anaerobic component, should be used with caution.

Acknowledgements The authors thank cycle efficiency experts Dr James Hopker and Dr Simon Jobson for assistance in protocol design and the statistician Dr Sabina Hulbert for her advice and verification of the statistical analysis of data.

Contributors SM with assistance from experts in cycle efficiency, Dr Hopker and Dr Jobson, and KW-M developed the research protocol. SM conducted data collection and assisted in editing. KW-M conducted data analysis and report writing. Both authors contributed in gaining ethical approval and administrative procedures.

Competing interests None declared.

Provenance and peer review Not commissioned; internally peer reviewed.

Open Access This is an Open Access article distributed in accordance with the Creative Commons Attribution Non Commercial (CC BY-NC 4.0) license, which permits others to distribute, remix, adapt, build upon this work noncommercially, and license their derivative works on different terms, provided the original work is properly cited and the use is non-commercial. See: http:// creativecommons.org/licenses/by-nc/4.0/

\section{REFERENCES}

1. British Heart Foundation (BHF). Coronary heart disease statistics in England, 2012. Bhf.or.uk/statistics.

2. Hansen JE, Sue DY, Oren A, Darryl YS, et al. Relation of oxygen uptake to work rate in normal men and men with circulatory disorders. Am J Cardio/ 1987;59:669-74.

3. Massie BM, Conway M, Rajagopalan B, et al. Skeletal muscle metabolism during exercise under ischemic conditions in congestive heart failure. Evidence for abnormalities unrelated to blood flow. Circulation 1988;78:320-6.

4. Itoh $\mathrm{H}$, Taniguchi K, Koike A, et al. Evaluation of severity of heart failure using ventilatory gas analysis. Circulation 1990;81:II31.

5. Solal AC, Chabernaud JM, Gourgon R. Comparison of oxygen uptake during bicycle exercise in patients with chronic heart failure and in normal subjects. J Am Coll Cardiol 1990;16:80-5.

6. Takagi S, Murase N, Kime R, et al. Skeletal muscle deoxygenation abnormalities in early post-myocardial infarction. Med Sci Sports Exerc 2014;46:2062-9.

7. Savage PD, Toth MJ, Ades PA. A re-examination of the metabolic equivalent concept in individuals with coronary heart disease. $J$ Cardiopulm Rehabil Prev 2007;27:143-8.

8. Woolf-May K, Ferrett D. Metabolic equivalents during the $10-\mathrm{m}$ shuttle walking test for post-myocardial infarction patients. $\mathrm{Br} J$ Sports Med 2008;42:36-41.

9. deJong $A$. The metabolic equivalent: re-evaluating what we know about the MET. ACSMs Health Fit J 2010;14:43-6.

10. Meadows S, Woolf-May K. Metabolic equivalents for postmyocardial infarction patients during a graded treadmill walking test. JEP Online 2013;2:60-8.

11. Mitchell SH, Steele NP, Leclerc KM, et al. Oxygen cost of exercise is increased in heart failure after accounting for recovery costs. Chest 2003;124:572-9.

12. Association Chartered Physiotherapists in Cardiac Rehabilitation (ACPICR)available at. Standards for Physical Activity and Exercise in the Cardiac Population. 2015. http://acpicr.com/publications.

13. Gladden LB, Yates JW, Howley ET. Who needs a bag? Med Sci Sports Exerc 2012;44:288-9.

14. Hopker JG, Jobson SA, Gregson HC, et al. Reliability of cycling gross efficiency using the Douglas bag method. Med Sci Sports Exerc 2012;44:290-6.

15. Borg GA. Psychophysical bases of perceived exertion. Med Sci Sports Exerc 1982;14:377.

16. Péronnet $F$, Massicotte $D$. Table of nonprotein respiratory quotient An update. Can J Sport Sci 1991:16:23-9.

17. Cohen-Solal A, Laperche T, Morvan D, et al. Prolonged kinetics of recovery of oxygen consumption after maximal graded exercise in patients with chronic heart failure. Circulation 1995;91:2924-32.

18. Tanabe $\mathrm{Y}$, Takahashi M, Hosaka $\mathrm{Y}$, et al. Prolonged recovery of cardiac output after maximal exercise in patients with chronic heart failure. J Am Coll Cardiol 2000;35:1228-36.

19. Levy WC, Maichel BA, Steele NP, et al. Biomechanical efficiency is decreased in heart failure during low-level steady state and maximal ramp exercise. Eur J Heart Fail 2004;6:917-26.

20. Witte KK, Levy WC, Lindsay KA, et al. Biomechanical efficiency is impaired in patients with chronic heart failure. Eur $J$ Heart Fail 2007;9:834-8.

21. Mezzani A, Hamm LF, Jones AM, et al. European Association for Cardiovascular Prevention and Rehabilitation, American Association of Cardiovascular and Pulmonary Rehabilitation, Canadian Association of Cardiac Rehabilitation. Aerobic exercise intensity assessment and prescription in cardiac rehabilitation: a joint position statement of the European Association for Cardiovascular Prevention and Rehabilitation, the American Association of Cardiovascular and Pulmonary Rehabilitation and the Canadian Association of Cardiac Rehabilitation. Eur J Prev Cardiol 2013;20:442-67.

22. Suzuki Y. Mechanical efficiency of fast and slow twitch muscle fibres in man during cycling. JAP 1979;47:263-7.

23. Faria IE, Sjojaard G, Bonde-Petersen F. Oxygen cost during different pedalling speeds for constant power output. J Sports Med 1982;22:295-9.

24. Ferguson RA, Ball D, Krustrup $P$, et al. Muscle oxygen uptake and energy turnover during dynamic exercise at different contraction frequencies in humans. J Physiol 2001;536:261-71.

25. Solberg G, Robstad B, Skjonsberg $\mathrm{OH}$, et al. Respiratory gas exchange indices for estimating the anerobic threshold. Sport Sci Med 2005;4:29-36.

26. Woolf-May K, Meadows S, Kearney E. Exploring adaptations to the modified shuttle walking test. BMJ Open 2013;3:e002821.

27. Bruce RA, Kusumi F, Hosmer D. Maximal oxygen intake and nomographic assessment of functional aerobic impairment in cardiovascular disease. Am Heart J 1973;85:546.

28. Woolf-May K,Meadows S, Ferrett $\mathrm{D}$, et al . The suitability of using metabolic equivalents (METs) during the Bruce protocol for the determination of exercise intensity in post-myocardial infarction patients. BOSEM.

29. Wasserman K, Mcilroy MB. Detecting the threshold of anaerobic metabolism in cardiac patients during exercise. Am J Cardiol 1964:14:844-52. 
30. British Association of Cardiac Prevention and Rehabilitation (BACPR). The BACPR Standards and Core Components for Cardiovascular Disease Prevention and Rehabilitation. 2nd Ed. London: BACPR, 2012.

31. American Association of Cardiovascular and Pulmonary Rehabilitation AACVPR. Guidelines for Cardiac Rehabilitation and Secondary Prevention Programs. Champaign, Illinois: Human Kinetics, 2004

32. Koike A, Hiroe M, Adachi $\mathrm{H}$, et al. Anaerobic metabolism as an indicator of aerobic function during exercise in cardiac patients. $J$ Am Coll Cardiol 1992;20:120-6.

33. Solaini G, Baracca A, Lenaz G, et al. Hypoxia and mitochondrial oxidative metabolism. Biochimica et Biophysica Acta (BBA) Bioenergetics 2010;1797:1171-7.

34. Matsumura N, Nishijima H, Kojima S, et al. Determination of anaerobic threshold for assessment of functional state in patients with chronic heart failure. Circulation 1983;68:360-7.

35. Clark AL, Poole-Wilson PA, Coats AJ, et al. Exercise limitation in chronic heart failure: central role of the periphery. J Am Coll Cardiol 1996;28:1092-102.

36. Musch TI, Terrell JA. Myocardial infarction: rest and exercise. AJP 1992;269:H411-H419.

37. Mancini DM, Coyle E, Coggan A, et al. Contribution of intrinsic skeletal muscle changes to 31P NMR skeletal muscle metabolic abnormalities in patients with chronic heart failure. Circulation 1989;80:1338-46.

38. Sullivan MJ, Green HJ, Cobb FR. Skeletal muscle biochemistry and histology in ambulatory patients with long-term heart failure. Circulation 1990;81:518-27.
39. Kemp GJ, Thompson $\mathrm{CH}$, Stratton JR, et al. Abnormalities in exercising skeletal muscle in congestive heart failure can be explained in terms of decreased mitochondrial ATP synthesis, reduced metabolic efficiency, and increased glycogenolysis. Heart 1996;76:35-41.

40. Hughson RL, Smyth GA. Slower adaptation of VO2 to steady state of submaximal exercise with B-blockade. Eur J Appl Physiol Occup Physiol 1983;52:107-10.

41. Reents S. Sport and Exercise Pharmacology. Champaign, IL: Kinetics Human, 2000.

42. Hall PE, Kendall MJ, Smith SR. Beta blockers and fatigue. J Clin Pharm Ther 1984;9:283-91.

43. Moosmann B, Behl C. Selenoprotein synthesis and side-effects of statins. Lancet 2004;363:892-4.

44. Karlsson J. Metabolic adaptations to exercise: a review of potential beta-adrenoceptor antagonist effects. Am J Cardiol 1985;55: 48D-58.

45. Wilms B, Ernst B, Thurnheer M, et al. Correction factors for the calculation of metabolic equivalents (MET) in overweight to extremely obese subjects. Int J Obes 2014;38:1383-7.

46. Tompuri TT. Metabolic equivalents of task are confounded by adiposity, which disturbs objective measurement of physical activity. Front Physiol 2015;6:226.

47. Braun SR. Respiratory rate pattern In: Clinical Méthodes: The History, Physical and Laboratory Examinations. 3rd edn. International, Butterworth Publications, 1990. 